\title{
CASE REPORT OF SITUS INVERSUS AND ANNULAR PANCREAS WITH PREDUODENAL POTAL VEIN
}

Narendra Kumar A ${ }^{1}$, Lavanya Kannaiyan², Venkateshwar Perugu ${ }^{3}$

\section{HOW TO CITE THIS ARTICLE:}

Narendra Kumar A, Lavanya Kannaiyan, Venkateshwar Perugu. "Case Report of Situs Inversus and Annular Pancreas with Preduodenal Potal Vein". Journal of Evolution of Medical and Dental Sciences 2015; Vol. 4, Issue 60, July 27; Page: 10565-10567, DOI: 10.14260/jemds/2015/1524

ABSTRACT: This a case report of a neonate with situs inversus with duodenal obstruction secondary to annular pancreas in whom association of preduodenal portal vein and was noticed preoperatively. This association is extremely rare. It is known to produce a technical hazard in surgeries involving the duodenum or biliary channels. A side to side duodenoduodenostomy was performed successfully bypassing the annular pancreas and the anomalous vein.

INTRODUCTION: Situs inversus complicating neonatal intestinal obstruction presents a challenging complex. The presence of duodenal obstruction due to annular pancreas and preduodenal vein in situs inversus is an extremely rare association. ${ }^{1}$ The presence of the preduodenal makes it difficult to access the duodenum and biliary channel and it is technically challenging.

CASE REPORT: A 3 day old, term, female neonate born to non-consanguineous parents, delivered caesarian section presented with projectile bilious vomiting and failure to pass meconium. There was dextrocardia, upper abdomen fullness with bilious nasogastric aspirates. X-ray of the chest and abdomen showed dextrocardia with reversed double bubble sign. The echocardiogram confirmed the dextrocardia and the Ultrasound confirmed the situs inversus.

On surgical exploration the neonate was found to have situs inversus with duodenal obstruction secondary to annular pancreas. The portal vein was found coursing anterior to the duodenum over the annular pancreas. The portal vein drained into the liver after dividing into the right and left branches. A side to side duodenoduodenostomy was done anterior to the abnormal portal vein resorting it to the retroperitoneal position (normal course). Post-operative recovery was uneventful.

DISCUSSION: Preduodenal portal vein (PDPV) is a rare entity. ${ }^{2}$ It can present at any age. ${ }^{3}$ In new born it may present due to concomitant duodenal obstruction. The obstruction is usually intrinsic due to duodenal web, annular pancreas (As in our patient), malrotation, atresia. ${ }^{1}$ It is an early embryological vascular accident, due to the persistence of the caudal anastomosis of the vitelline vein. PDPV is rarely an isolated incident associated with Situs inversus or heterotaxia or with associated cardiac anomalies, asplenia or poly splenia, biliary atresia, duodenal atresia, malrotation. ${ }^{1}$

The presence of PDPV is important to identify as failure to do so may result in a surgical catastrophe where in the portal vein is inadvertently divided or ligated. ${ }^{2}$ Waldenschimdt ${ }^{4}$ suggested that incidentally detected PDPV in asymptomatic patients should not be corrected. Also in all patients with rotational anomalies a PDPV should be looked for. ${ }^{4}$ The surgical implications of PDPV are that it predisposes to iatrogenic bleeding, damage to the biliary tree or the distended duodenum ${ }^{2}$. Hence it is imperative to identify the presence of a PDPV in patients with situs inversus or associated anomalies. 
In duodenal obstruction due to the presence of a PDPV a bypass procedure, such as a duodenoduodenostomy or side to side duodenoduonestomy, duodenogastrosotmy or duodenojejunostomy ${ }^{1,2,3,4,5}$ are suggested. It is important to make a loose anastomosis so as to not obstruct the vein the future.

CONCLUSIONS: In those patients with situs inversus requiring laparotomy it is important to look for the presence of a PDPV, especially when associated with rotational anomalies or duodenal obstruction. The potential for a surgical catastrophe cannot be underestimated. A preoperative radiological identification will aide in the surgical approach.

\section{REFERENCES:}

1. Baglaj M, Gerus S. Preduodenal portal vein, malrotation, and high jejunal atresia: a case report Journal of Pediatric Surgery (2012) 47, E27-E30.

2. Shukla RM, Mukherjee PP, Mukhopadhyay B, Manda KC. Congenital Duodenal Obstruction with Preduodenal Portal Vein and Situs Inversus Totalis: Report of Two Cases and Literature Review. Indian J Surg (June 2013) 75(Suppl 1):S74-S76.

3. Mordehai J, Cohen Z, Kurzbart E, Mares AJ. Preduodenal Portal Vein Causing Duodenal Obstruction Associated With Situs Inversus, Intestinal Malrotation, and Polysplenia: A Case Report Journal of Pediatric Surgery, Vol 37, No 4 (April), 2002: E5.

4. Waldschmidt J (1990) Das akute Abdomenim Kindesalter. Edition Medizin, VCH Verl., Weinheim.

5. Ohno K, Nakamura T, Azuma T, Yoshida T, Hayashi H, Nakahira M, Nishigaki K, Kawahira Y, Ueno TE valuation of the portal vein after duodenoduodenostomy for congenital duodenal stenosis associated with the preduodenal superior mesenteric vein, situs inversus, polysplenia, and malrotation. Journal of Pediatric Surgery (2007) 42, 436- 439.

Figure 1: Intraoperative pictures of preduodenal vein with arrows marking the preduodenal portal vein, causing compression of the duodenum.

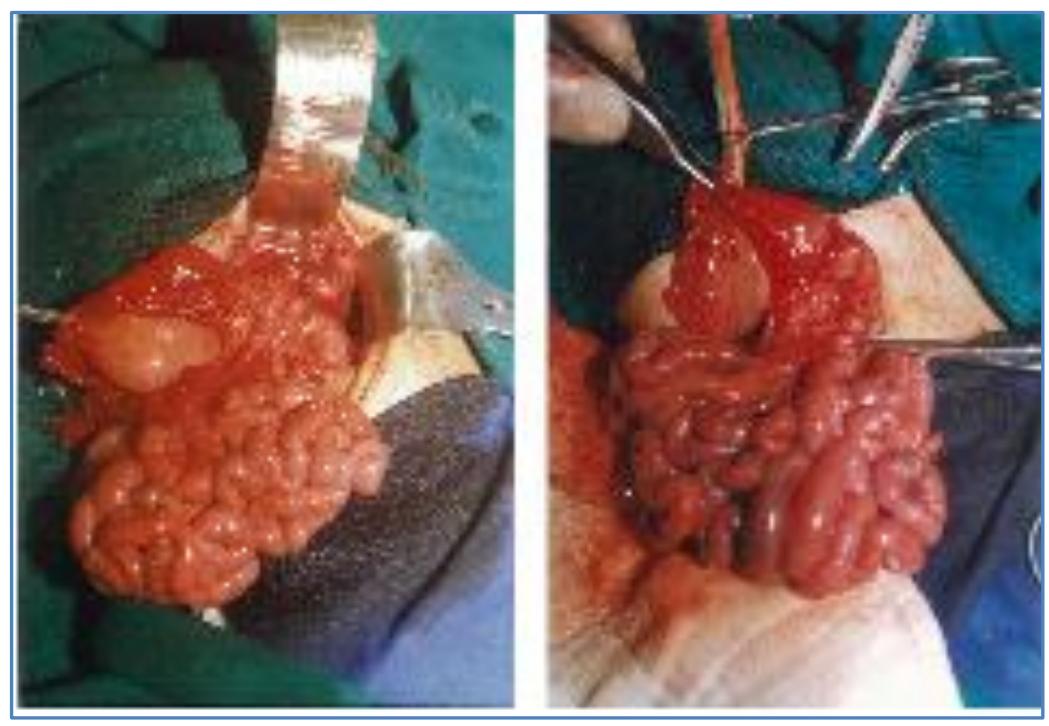




\section{CASE REPORT}

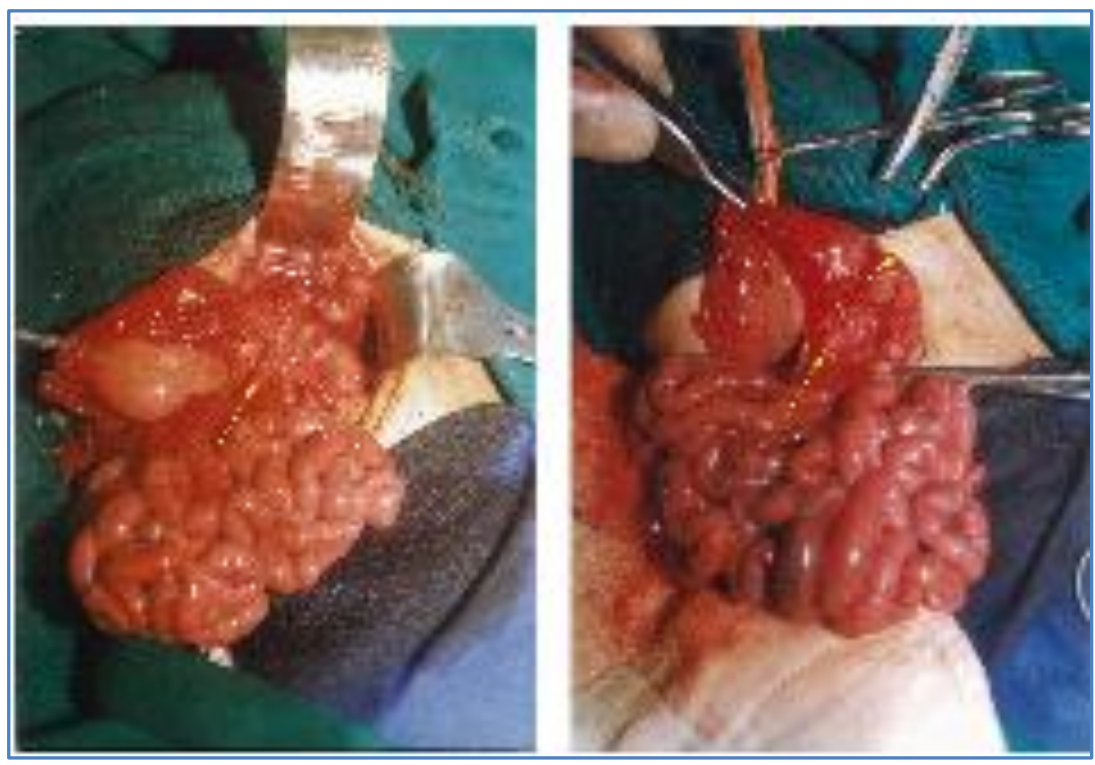

Fig. 1

\section{AUTHORS:}

1. Narendra Kumar A.

2. Lavanya Kannaiyan

3. Venkateshwar Perugu

\section{PARTICULARS OF CONTRIBUTORS:}

1. Chief Pediatric Surgeon, Department of Paediatric Surgery, Lotus Children's Hospitals, Hyderabad, Telalgana, India.

2. Pediatric Surgeon, Department of Paediatric Surgery, Lotus Children's Hospitals, Hyderabad, Telalgana, India.

FINANCIAL OR OTHER COMPETING INTERESTS: None
3. Pediatric Surgeon, Department of Paediatric Surgery, Lotus Children's Hospitals, Hyderabad, Telalgana, India.

\section{NAME ADDRESS EMAIL ID OF THE} CORRESPONDING AUTHOR:

Dr. Narendra Kumar A, 304, Lake Villa Apartments, 6-3-1186/87, Green Lands, Begumpet, Hyderbad- 500016

Telangana, India.

E-mail: naren.are.1961@gmail.com

Date of Submission: 27/06/2015. Date of Peer Review: 28/06/2015. Date of Acceptance: 20/07/2015. Date of Publishing: 27/07/2015. 